\title{
Are Droppings, Distance From Pastoralist Camps, and Pika Burrows Good Proxies for Local Grazing Pressure?
}

\author{
Tsechoe Dorji, ${ }^{1,2}$ Ørjan Totland, ${ }^{3}$ and Stein R. $\mathrm{Moe}^{3}$
}

\begin{abstract}
Authors are ${ }^{1} \mathrm{PhD}$ candidate and ${ }^{3}$ Professor, Department of Ecology and Natural Resource Management, Norwegian University of Life Sciences, NO-1432 Ass, Norway; and ${ }^{2}$ Lecturer, Department of Plant Science and Technology, Tibet Agriculture and Animal Husbandry College, Bayi, Nyingchi, 860000, Tibet Autonomous Region, China.
\end{abstract}

\begin{abstract}
Grazing is regarded as one of the most important factors influencing rangeland ecosystems. Many previous studies have used indirect measures (proxies) of grazing intensity, such as the distance from congregation areas and the number of herbivore excreta, to estimate effects of grazing on vegetation parameters in rangeland ecosystems. However, little is known about how such proxies reflect the true grazing intensity, and if their suitability is consistent across landscape conditions. We measured grazing intensity based on the amount of plant ramets being grazed in 75 plots positioned across a rangeland landscape in central Tibet. Several grazing intensity proxies (distance from pastoral camp sites, number of yak dung patches (old and fresh), sheep and goat dropping piles, and pika (Ochotona curzoniae) burrows (active and abandoned)) were also measured in each plot. Regression models were used to examine the suitability of these proxies in predicting our measure of real grazing intensity. None of the examined proxies satisfactorily predicted real grazing intensity in our study system. The distance from camp sites was the best proxy for grazing intensity $(P<0.001)$, but it explained only $30 \%$ of its variation. Fresh yak dung and active pika burrows explained only $10 \%$ and $3 \%$ of the variation in grazing intensity, respectively. The suitability of using proxies for grazing intensity did not significantly differ along landscape parameters (elevation, aspect directions, and slope angle) $(P>0.05)$, except that the number of animal excreta and pika burrows functioned better as proxies at low, compared to high, elevation $(P<0.05)$. Our results should be of concern since many studies use proxies to estimate effects of grazing on vegetation dynamics and ecosystem properties. We recommend awareness of potential limitations and suitability of proxies, when real grazing intensity is not measured.
\end{abstract}

Key Words: Alpine region, grazing intensity, pika, Tibetan plateau, yak

\section{INTRODUCTION}

Grazing is regarded as one of the most important drivers of changes in biogeochemical cycles (Pineiro et al. 2006), plant physical structure (Veeneklaas et al. 2011), population dynamics (Milchunas and Lauenroth 1993; Cingolani et al. 2005), and species composition (Milchunas and Lauenroth 1993; Cingolani et al. 2005; Zhou et al. 2006) in rangeland ecosystem. Heavy grazing may cause rangeland degradation by reducing plant population density and species diversity, while moderate grazing intensity could increase the number and abundance of coexisting species (Roxburgh et al. 2004). Many previous studies have used indirect measures (proxies), such as distance from herbivore congregation areas (Pickup and Chewings 1994; Adler and Hall 2005; Karnieli et al. 2008; Sasaki et al. 2009; Dorji et al. 2010; Manthey and Peper 2010; Tarhouni et al. 2010), number of herbivore excreta (Lange 1969; Barnes 2001; Hendricks et al. 2005; Barnes et al. 2008), and small herbivore burrows (Jiang 1998; Lai and Smith 2003; Sun et al. 2011) to estimate effects of grazing on vegetation

The research was a part of T.D.'s PhD research project, funded by the University Cooperation, Tibet-Norway Network.

Correspondence: Tsechoe Dorji, Department of Ecology and Natural Resource Management, Norwegian University of Life Sciences, PO Box 5003, N0-1432 Ås, Norway. Email: tsechoedorji@gmail.com

Manuscript received 1 February 2012; manuscript accepted 5 August 2012.

(c) 2013 The Society for Range Management parameters in rangeland ecosystems. However, the suitability of these proxies has rarely been tested.

Grazing intensity is assumed to decrease with the distance from congregation areas (Pickup and Chewings 1994; Tarhouni et al. 2010), but such a relationship is not always linear (Fernandez-Gimenez and Allen-Diaz 2001; Manthey and Peper 2010). Grazing intensity is also thought to increase with number of herbivore excreta (Hendricks et al. 2005; Barnes et al. 2008), but density of droppings may not reflect the true grazing intensity at a local scale since herbivores may defecate at one place and graze at another because they may reject vegetation around excreta (Omaliko 1981). Moreover, the spatial distribution of grazing animals is heterogeneous (Coughenour 1991; Bailey et al. 1996; Barnes et al. 2008), and the use of direct counts of herbivore excreta as a parameter of grazing intensity may therefore give erroneous estimates. Although the number of burrows may indicate density of burrowing herbivores (e.g., lagomorphs and rodents), these animals may travel far from burrows to forage, particularly when predation risk is low (Lovegrove and Painting 2008).

Although various proxies are frequently used as surrogates for grazing intensity, little is known about their ability to satisfactorily estimate true grazing intensity. In addition, the suitability of these proxies may vary across the landscape. It is possible that the behavior and activity of grazing animals change with, for example, aspect, slope, and elevation, and also that the relationship between proxies of grazing intensity and the real grazing intensity may vary in direction, strength, and 
significance across a landscape. However, to the best of our knowledge no previous studies have examined the suitability of grazing-intensity proxies across landscape properties.

In this paper we examine if distance from pastoral camp sites, number of yak dung patches, sheep and goat dropping piles, and pika (Ochotona curzoniae) burrows can be used to predict grazing intensity across a rangeland landscape in the Nam Tso region, central Tibet, China. In addition, we ask if the suitability of each proxy is consistent across contrasting topographic conditions of the landscape.

\section{METHODS}

\section{Study Site}

The study site consisted of approximately $50 \mathrm{~km}^{2}$ of south, west, and north facing hillslopes in the Nam Tso region, central Tibet, China (lat $30^{\circ} 41.208^{\prime} \mathrm{N}-30^{\circ} 44.579^{\prime} \mathrm{N}$; long $91^{\circ} 01.117^{\prime} \mathrm{E}-91^{\circ} 04.590^{\prime} \mathrm{E}$ ) at the base of the Nyenchentangula mountain range. The mean annual temperature and precipitation is $-0.6^{\circ} \mathrm{C}$ and $414.6 \mathrm{~mm}$, respectively, in Nam Tso region, occurring mainly during the summer season from June to September (Kang et al. 2011). The site is an alpine meadow grassland, with Kobresia pygmaea C. B. Clarke as the dominant species. The study site was selected because it has a long history as an important summer grazing area for local pastoralists and represents typical summer pastures in the region. Moreover, it has a substantial gradient in grazing intensity across landscape conditions. According to local administration statistics there were 869 yaks, 2370 sheep, 458 goats, and 26 horses in the area in 2009 , belonging to 32 pastoral families. The only abundant wild herbivore in the area is pika, which may be most abundant at lower elevation (Wang et al. 2004). An increasing livestock population and the high abundance of pika have been blamed for the degradation of the rangeland and the poor grazing conditions in the region $(\mathrm{Li}$ and Huang 1995). It has been suggested that livestock grazing during past several thousand years is the driving force of the current alpine meadow landscapes on the central Tibetan Plateau (Miehe et al. 2008).

Locals collect yak dung (mostly dry) for fuel, mainly nearby their camp sites. Local camp sites are located at valley bottoms with easy access to water sources and roads. Yaks are left unguarded as semi free-ranging livestock from morning to evening and are herded back to camp sites every evening. Sheep herders normally herd sheep and goats far from the camps for better forages from morning to late noon, and then herds are taken back to camp sites for milking for about one hour. After milking they are released for grazing near the camp sites and then kept in camp overnight. We calculated metabolic biomass of each herbivore species in order to infer relative contribution of each species to total grazing intensity. The metabolic biomass of livestock was calculated as body weight of each species powered by 0.75 and then multiply by the number of each livestock species (Kleiber 1961). The metabolic biomass of yak, sheep, and goats in our study site $\left(50 \mathrm{~km}^{2}\right)$ are 51323 $\left(230^{0.75} \times 869\right), 44563\left(50^{0.75} \times 2370\right)$, and 5841 $\left(29.8^{0.75} \times 458\right) \mathrm{kg}$, respectively. Data on body weight of yak, sheep, and goats were obtained from Long et al. (1999), Zhao and Zhou (1999), and Misra et al. (1998), respectively. The population density of pika (PDP) was estimated using a regression equation reported by Pech et al. (2007), where $\mathrm{PDP}=-3.4+0.0125 \times$ number of active burrows. The estimated number of active burrows in our study site $\left(50 \mathrm{~km}^{2}\right)$ is $3400000\left(6.8\right.$ burrows $\left.\cdot 100 \mathrm{~m}^{-2}\right)$. Thus, the PDP is 42496.6 pika $50 \mathrm{~km}^{-2}(-3.4+0.0125 \times 3400000)$. The average weight of adult pika is $0.154 \mathrm{~kg}$ (Nie 2005). Thus, the metabolic biomass of pika in our study site is $10447 \mathrm{~kg}\left(0.154^{0.75}\right.$ $\mathrm{kg} \times 42496.6$ pika).

\section{Study Design}

Seven hillslopes with similar vegetation were selected nearby local pastoralist summer camps to study relationships between grazing intensity and its proxies. The hillslopes were stratified into five elevation zones that spanned 60 elevation meters across a total elevation gradient from 4800-5100 m. Each hillslope was further categorized into three aspect directions (south, west, and north), yielding 15 sectors corresponding to each combination of elevation zone and aspect direction. One sampling plot of $10 \times 10 \mathrm{~m}$ was positioned as close as possible in the center of each sector (by visually identifying the center from the upper elevation limit of each sector), without previous observation of the vegetation and proxies on the ground. Thus, this procedure yielded a randomly sampled and representative data set of vegetation and proxies across the study area. A maximum of 15 plots (one for each sector) were positioned on any hillslope, and each combination of elevation zone and aspect were replicated five times on the hillslopes, yielding 75 plots in total across the study area (5 elevation zones $\times 3$ aspects $\times 5$ replicates $=75$ plots $)$. Since the hillslopes were spatially independent from each other and distributed over the whole study area, sampling plots that represent each combination of elevation zone and aspect were also spatially independent. In each sampling plot, five quadrats of $1 \times 1 \mathrm{~m}$ were systematically located with one in each corner and one in the center of the plot, totaling 375 quadrats within the 75 plots.

\section{Data Collection}

To measure grazing intensity, we recorded the visually observed proportion of individual plant parts grazed by herbivores. Between 10 and 15 ramets from each of six grass and sedge species (Poa hirtiglumis var. Hook. f. var. nimuana (C. Ling) Soreng et, Poa pagophila Bor, Carex incurva Lightf, Carex moocroftii Falc. ex Boott, K. pygmaea, K. schoenoides (C. A. Meyer) Steudel) were randomly selected from each of the five quadrats within each plot for visual estimation. If fewer than 10 ramets of a species were present in a quadrat, all ramets present were selected. Grazing intensities for each species in each quadrat were scored from zero to three, based on the amount of each ramet being grazed, with zero for no grazing, one for less than one third of the ramet being grazed, two for half of the ramet (ranged approximately between one third to two third of the ramet) being grazed, and three for more than two thirds of the ramet being grazed. Grazing intensities for each inspected species from the five quadrats in each plot were averaged to obtain plot level grazing intensity for each inspected species. The average total grazing intensity of each plot was then derived by averaging the plot level grazing intensity of all inspected plant species that occurred in each 
Table 1. Correlation coefficient matrix of variables (DFC, distance from pastoralist camp site; YDF, number of fresh yak dung patches; YD0, number of old yak dung patches; YDT, number of total yak dung patches; PBA, number of active pika (Ochotona curzoniae) burrows; PBO, number of abandoned pika burrows; PBT, number of total pika burrows; SG, number of sheep and goat's dropping piles; EV, elevation; AS, aspect; SL, slope angle) measured in central Tibet 2009. Column names correspond to abbreviations indicated in row names. Bold numbers indicate correlation coefficient above 0.5.

\begin{tabular}{|c|c|c|c|c|c|c|c|c|c|c|c|}
\hline & DFC & YDF & YDO & YDT & PBA & $\mathrm{PBO}$ & PBT & $S G$ & EV & AS & SL \\
\hline \multicolumn{12}{|l|}{ Grazing intensity proxies } \\
\hline Distance from camps (DFC) & 1.00 & & & & & & & & & & \\
\hline Fresh yak dung patches (YDF) & -0.23 & 1.00 & & & & & & & & & \\
\hline Old yak dung patches (YDO) & 0.04 & 0.33 & 1.00 & & & & & & & & \\
\hline Total yak dung patches (YDT) & -0.11 & 0.80 & 0.83 & 1.00 & & & & & & & \\
\hline Active pika burrows (PBA) & -0.24 & 0.25 & 0.22 & 0.29 & 1.00 & & & & & & \\
\hline Abandoned pika burrows (PBO) & -0.18 & 0.28 & 0.35 & 0.39 & 0.62 & 1.00 & & & & & \\
\hline Total pika burrows (PBT) & -0.23 & 0.30 & 0.31 & 0.37 & 0.92 & 0.88 & 1.00 & & & & \\
\hline Sheep and goat dropping piles (SG) & -0.29 & 0.27 & 0.13 & 0.24 & 0.04 & 0.03 & 0.04 & 1.00 & & & \\
\hline \multicolumn{12}{|l|}{ Landscape variables } \\
\hline Elevation (EV) & 0.91 & -0.24 & -0.01 & -0.15 & -0.29 & -0.18 & -0.27 & -0.27 & 1.00 & & \\
\hline Aspects (AS) & -0.16 & -0.09 & -0.14 & -0.15 & -0.22 & -0.19 & -0.23 & -0.02 & -0.13 & 1.00 & \\
\hline Slopes (SL) & 0.44 & -0.38 & -0.22 & -0.37 & -0.09 & -0.04 & -0.07 & -0.33 & 0.59 & -0.05 & 1.00 \\
\hline
\end{tabular}

plot. The total grazing intensity of each plot was used as the true grazing intensity in this study. Forbs or other plant functional types were not inspected for grazing intensity because it was hard to assess if these plants were actually grazed and consequently the proportion of plants being grazed could not be assessed. Moreover, the measured species constitute the dominant part of the vegetation and are important forage for yak, sheep, goat, and pika.

The grazing intensity proxies considered here are the distance from camp sites, the inverse distance from camp sites, the number of yak dung patches (distinguishing fresh and old), sheep and goat dropping piles, and pika burrows (distinguishing abandoned and active) (Tables 1 and 2). The distance from camp sites was the average linear aerial distance from each plot to the nearest three pastoralist camp sites, using geographic coordinates. We used the inverse distance from pastoral camp sites to fit variation in grazing intensity, because the grazing intensity may fit better to the inverse distance (Fernandez-Gimenez and Allen-Diaz 2001; Manthey and Peper 2010). Fresh and old yak dung patches were counted in each plot, whereas sheep and goat dropping piles were counted in each quadrat and averaged over the five quadrats in each plot. Sheep and goat grazing were merged into one variable, because their droppings were difficult to distinguish and because they have a similar foraging behavior on the Tibetan plateau (Cincotta et al. 1991). The number of pika burrows, both active and abandoned, were recorded in each plot (Lai and Smith 2003). Burrows with fresh pika tracks, droppings, and topsoil nearby openings were defined as active, while burrows with spider webs and old dirt piles (sometimes with vegetation grown on the dirt piles) were defined as abandoned. Slope angles, aspect directions, and elevation were also measured to examine if the proxies differed in their ability to estimate real grazing intensity under different topographical conditions. Geographic coordinates and elevation data were obtained for each sampling plot using a global positioning system (GPS) devise. Aspect and slope data were obtained for each sampling plot using a standard compass.

\section{Statistical Analyses}

To explore how the grazing intensity proxies predict the true grazing intensity, we used a set of linear regression models

Table 2. Summary statistic (mean, standard deviation [SD], quantiles, and the number of observation [N]) of real grazing intensity and proxies (distance from pastoralist's camp site, number of fresh, old, and total yak dung patches, number of active, abandoned, and total pika (Ochotona curzoniae) burrows, number of sheep and goat dropping piles) measured in central Tibet 2009.

\begin{tabular}{|c|c|c|c|c|c|c|c|c|}
\hline & \multirow[b]{2}{*}{ Mean } & \multirow[b]{2}{*}{ SD } & \multicolumn{5}{|c|}{ Quantiles } & \multirow[b]{2}{*}{$N$} \\
\hline & & & $0 \%$ & $25 \%$ & $50 \%$ & $75 \%$ & $100 \%$ & \\
\hline Grazing intensity & 1.64 & 0.47 & 0.80 & 1.28 & 1.63 & 2.00 & 2.93 & 75 \\
\hline \multicolumn{9}{|l|}{ Proxies } \\
\hline Distance from camp sites & 1140.7 & 507.7 & 428.0 & 723.8 & 1012.3 & 1587.0 & 2158.7 & 75 \\
\hline Old yak dung & 2.41 & 2.05 & 0 & 1 & 2 & 4 & 10 & 75 \\
\hline Fresh yak dung & 1.51 & 1.93 & 0 & 0 & 1 & 2 & 8 & 75 \\
\hline Total yak dung & 3.92 & 3.25 & 0 & 1 & 3 & 6 & 14 & 75 \\
\hline Sheep and goat dropping piles & 0.20 & 0.22 & 0 & 0 & 0.2 & 0.4 & 1 & 75 \\
\hline Active pika burrows & 6.80 & 5.89 & 0 & 3 & 5 & 9 & 27 & 75 \\
\hline Abandoned pika burrows & 5.48 & 4.97 & 0 & 2 & 5 & 8.5 & 27 & 75 \\
\hline Total pika burrows & 12.28 & 9.79 & 0 & 5 & 11 & 16 & 42 & 75 \\
\hline
\end{tabular}


Table 3. Simple linear regression models on the relationship between grazing intensity (dependent variable) and each grazing intensity proxies (number of active, abandoned, and total pika (Ochotona curzoniae) burrows, number of fresh, old, and total yak dung patches, number of sheep and goat's dropping piles, and distance from camp sites) (as predictor variables) in central Tibet 2009. All grazing intensity proxy variables were log transformed.

\begin{tabular}{llrr}
\hline \multicolumn{1}{c}{ Grazing proxies } & \multicolumn{1}{c}{ Model } & $R^{2 \mathrm{a}}$ & \multicolumn{1}{c}{$P^{\mathrm{b}}$} \\
\hline Pika burrows & & & \\
$\quad$ Active & $y=1.513+0.072 x$ & 0.018 & 0.244 \\
$\quad$ Abandoned & $y=1.531+0.07 x$ & 0.017 & 0.268 \\
$\quad$ Total & $y=1.512+0.057 x$ & 0.014 & 0.309 \\
Yak dung & $y=1.493+0.218 x$ & 0.104 & 0.005 \\
$\quad$ Fresh & $y=1.487+0.146 x$ & 0.041 & 0.080 \\
Old & $y=1.401+0.176 x$ & 0.081 & 0.013 \\
Total & $y=1.538+0.601 x$ & 0.047 & 0.062 \\
Sheep and goat dropping piles & $y=-2.119+25.951 / x^{\mathrm{c}}$ & 0.270 & $<0.001$ \\
Distance from pastoralist & $y=5.478-0.553 \mathrm{~d} / x^{\mathrm{d}}$ & 0.299 & $<0.001$ \\
$\quad$ camp sites & $y=5 r$
\end{tabular}

${ }^{a} G o o d n e s s$ of fit $\left(R^{2}\right)$ for corresponding linear model.

${ }^{\mathrm{b}} P$ values for corresponding linear model or variable that involved in the model (because they are simple linear regression models).

'Inverse distance from camp site.

dDistance from camp site.

using each proxy as explanatory variables and real grazing intensity as the response. Separate linear regressions (one for each proxy), including interaction terms between the proxy and each topographic parameter (elevation, slope, and aspects) as explanatory variables, were used to examine if the suitability of each proxy varied across landscape conditions. Main effects of topographic parameters were not included in the linear

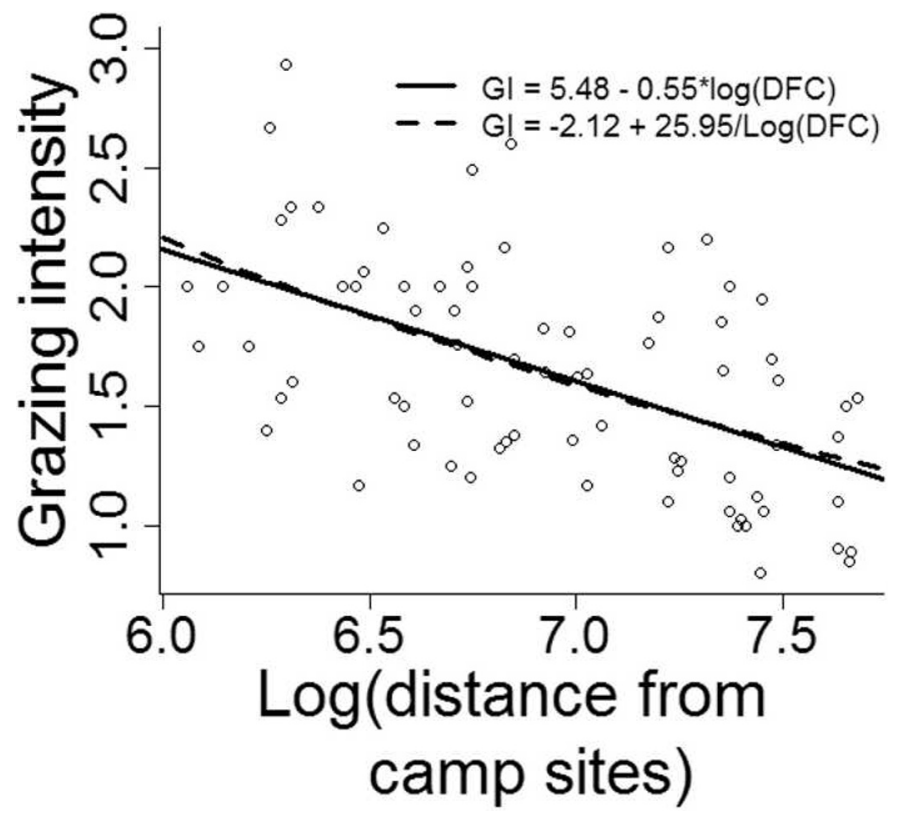

Figure 1. Relationship between grazing intensity (see methods for calculation) and distance from camp sites (meters) in central Tibet 2009. Model parameters and $R^{2}$ and $P$ values are shown on the graph. Gl, grazing intensity; DFC, distance from pastoralist camp sites. DFC was log transformed.
Table 4. $P$ values of interactions between landscape variables (elevation, aspect direction, and slope angle/steepness) and grazing intensity proxies (number of active, abandoned, and total pika [Ochotona curzoniae] burrows, number of fresh, old, and total yak dung patches, number of sheep and goat's dropping piles, and distance from camp sites) in predicting real grazing intensity in central Tibet 2009. All grazing intensity proxy variables were log transformed.

\begin{tabular}{llll}
\hline \multicolumn{1}{c}{ Grazing proxies } & Elevation & Aspect & Slope $^{1}$ \\
\hline Pika burrows & & & \\
$\quad$ Active & 0.002 & 0.56 & 0.742 \\
$\quad$ Abandoned & 0.0009 & 0.248 & 0.885 \\
$\quad$ Total & 0.0007 & 0.350 & 0.804 \\
Yak dung & & & \\
$\quad$ Fresh & 0.120 & 0.354 & 0.175 \\
$\quad$ Old & 0.003 & 0.274 & 0.376 \\
$\quad$ Total & 0.004 & 0.416 & 0.246 \\
Sheep and goat's dropping piles & 0.0006 & 0.410 & 0.145 \\
Distance from pastoralist camp sites & 0.758 & 0.312 & 0.520 \\
\hline
\end{tabular}

${ }^{1}$ Slope steepness (slope angle) of area where sampling was positioned.

regression analyses because we were only interested in the suitability of each proxy as an estimate of real grazing intensity across landscape conditions. A multiple linear regression analysis was also conducted to examine relative importance of each proxy in explaining variation in real grazing intensity and how much variation in grazing intensity was explained by all proxies together and by their interactions with topographic parameters. Total yak dung and total pika burrows were not included in the multiple regression analysis because these two variables are highly correlated with fresh and old yak dung, and active and abandoned pika burrows, respectively (Table 1). Variables with skewed distribution and variance larger than means (Table 2) were $\log$-transformed $(\log (x)$ or $\log (x+1))$ (Quinn and Keough 2002). A series of diagnostic analyses were performed for each model to examine model adequacy (Johnson and Wichern 2007). The regression analyses and its relevant plots were generated by using R 2.13.2. (R Development Core Team 2012) .

\section{RESULTS}

Simple linear regression showed that the distance from camp sites was the best possible proxy for grazing intensity $(P<0.001)$, but it only explained $30 \%$ of its variation (Tables 2 and 3). Grazing intensity linearly decreased with the distance from camp sites (Fig. 1). Although grazing intensity significantly increased with number of fresh and total yak dung $(P<0.01)$, they explained less than $11 \%$ of variation in grazing intensity (Tables 2 and 3). Sheep and goat dropping piles and active pika burrows explained only $4 \%$ and $3 \%$ of the variation in grazing intensity, respectively (Tables 2 and 3 ).

The suitability of using active, abandoned, and total pika burrows, old and total yak dung, and sheep and goat dropping piles as proxy for grazing intensity decreased with elevation, as revealed by significant interactions between the proxies and elevation (Tables 2 and 4; Figs. 2 and 3). None of the other interactions between proxies and landscape variables were 

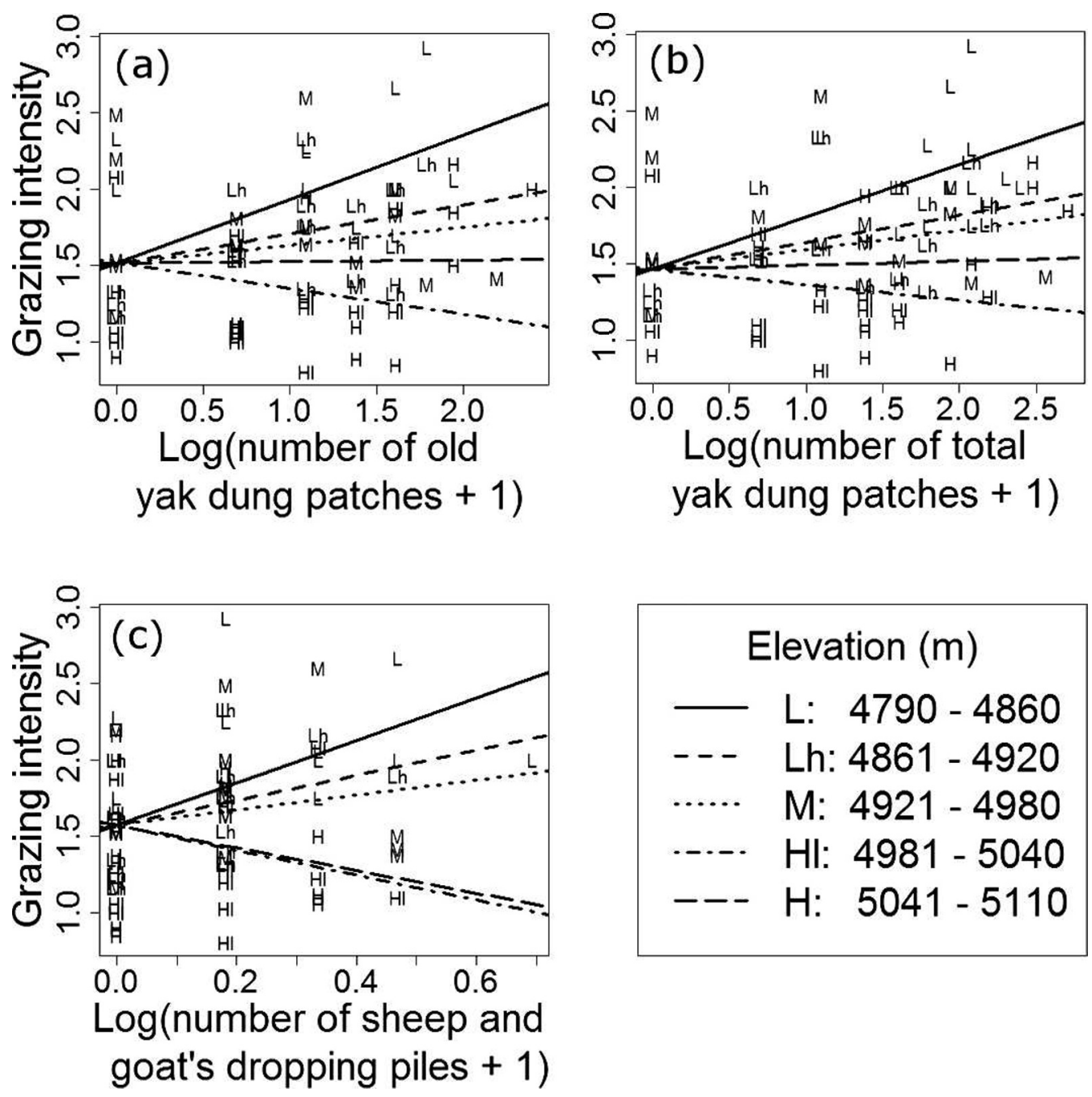

Figure 2. Interaction terms between elevation and number of old (a) and total (b) yak dung patches and number of sheep and goat's dropping piles (c) on real grazing intensity (see method for calculation) in central Tibet 2009. Because the main effects of elevation were not included in the models (see detail in method section), the intercepts of regression lines on each graph is similar. All grazing intensity proxy variables were log transformed.

significant $(P>0.05)$ (Table 4). Multiple regression model showed that all proxies together explained only $38 \%$ of variation in grazing intensity, among which only the distance from camp sites was significant in the full model (Table 5).

\section{DISCUSSION}

Our results suggest that none of the grazing intensity proxies we examined satisfactorily reflects our measure of real grazing intensity. Although many studies have used changes in vegetation parameters (e.g., vegetation cover, species richness and composition) at increasing distance from herbivore congregation areas to infer the effects of grazing intensity on ecosystems in different parts of the world (Pickup and Chewings 1994; Pickup et al. 1998; Ludwig et al. 1999; Pringle and Landsberg 2004; Adler and Hall 2005; Karnieli et al. 2008; Sasaki et al. 2009; Dorji et al. 2010; Manthey and Peper 2010; Tarhouni et al. 2010), we found that the distance from camp sites explained only $30 \%$ of variation in grazing intensity. Several mechanisms may contribute to the low explanatory power of distance from camp sites. First, Adler and Hall (2005) reported that the distance from domestic herbivore congregation areas, such as pastoralists' camp sites, represents a cumulative, but not necessarily the current, grazing intensity. Second, since wild herbivores may avoid humans (Fox and Bårdsen 2005), grazing may actually be more intense far from local camps. Third, the suitability of the distance from camp sites as a proxy for grazing intensity may depend on topographic features, such as the elevation, aspect, and slope expositions. We argue that the second and third mechanisms do not apply in our study system. First, the total number of pika burrows, which may reflect the grazing intensity of the only dominant wild herbivore species in the region, decreased significantly with distance from camp site $(R=-0.23$, $P=0.05)$. Thus, there should be no opposing effects of wildlife and livestock grazing along the distance from camp sites. Second, we did not find any interactions between the distance from camp sites and topographic parameters in predicting the grazing intensity, indicating that the suitability of distance from camp sites as a proxy for grazing intensity did not depend on topographic conditions. However, we acknowledge that the 

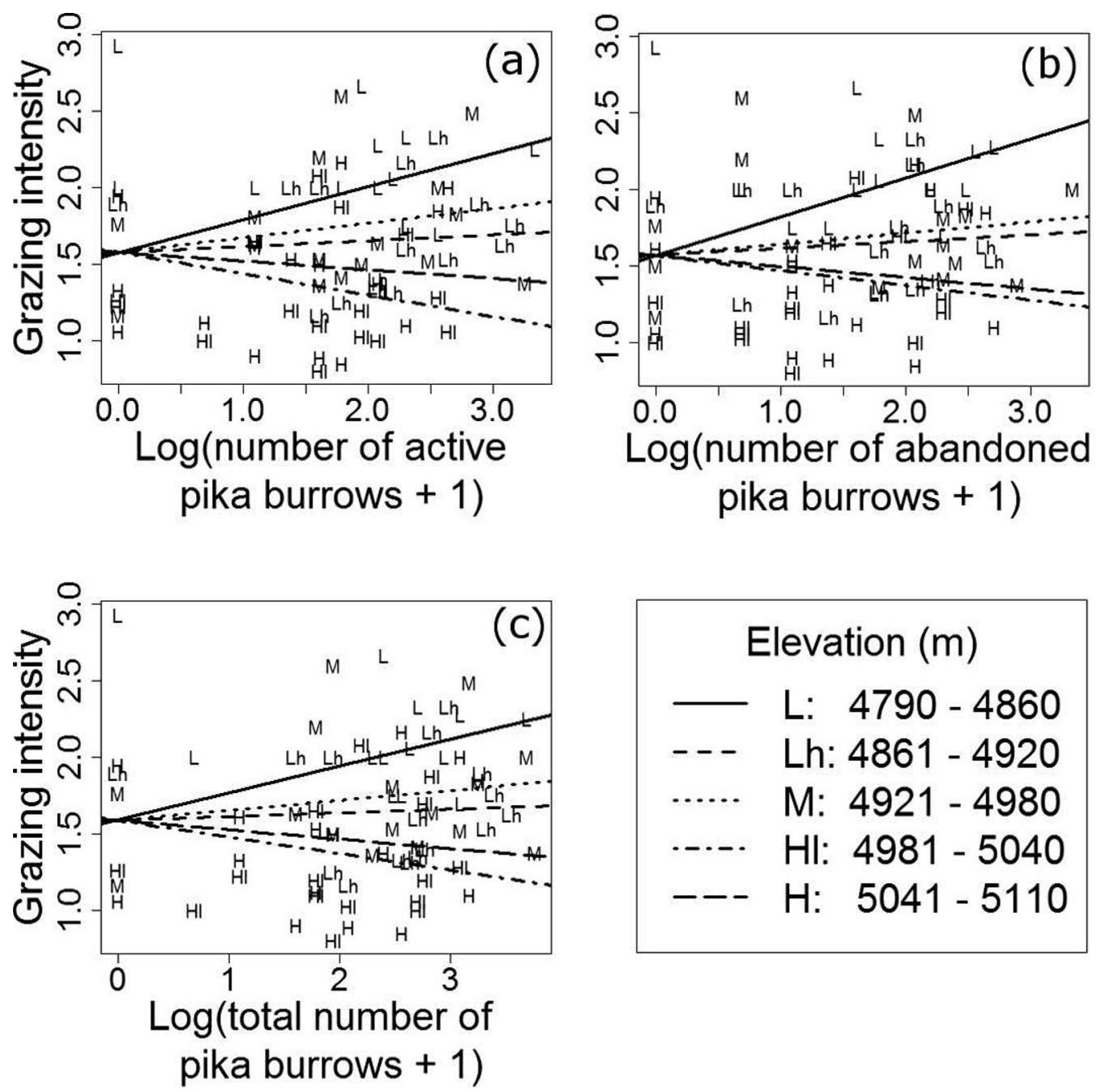

Figure 3. Interaction terms between elevation and number of active (a), abandoned (b), and total (c) pika (Ochotona curzoniae) burrows on real grazing intensity (see Methods for calculation) in central Tibet 2009. Because the main effects of elevation were not included in the models (see detail in Methods), the intercepts of regression lines on each graph is similar. All grazing intensity proxy variables were log transformed.

grazing intensity we measured was a one-time measurement. Thus, it may not completely reflect the historical grazing pressure that could be associated with the distance from camp sites. Moreover, the suitability of the distance from camp sites as a proxy for grazing intensity may also depend on heterogeneity in vegetation types, forage availability, and disturbance patterns across the landscape, because free-ranging herbivores, in particular, may tend to congregate at areas with higher forage availability and avoid disturbances. This situation may further reduce the suitability of distance from camp sites as a proxy for grazing intensity in a heterogeneous landscape. Grazing intensity was not inversely related to the distance from camp sites, as proposed by Manthey and Peper (2010). However, the nearest plot was $428 \mathrm{~m}$ away from any camp. Thus, the expected "piosphere" discussed by Manthey and Peper (2010) was not accounted for in our study, which may have resulted in a linear, rather than an inverse, relationship between grazing intensity and distance from camp sites.

Although the density of animal dung is often used as surrogate for grazing intensity, we found that none of the animal dung parameters we examined satisfactorily explained variation in real grazing intensity. It is possible that the animals mainly defecate at one place and graze at another (Omaliko 1981), especially where a large grazing area permits longdistance movements. This is especially evident in our study, because the suitability of herbivore excreta in predicting the real grazing intensity was highest at low elevation where livestock density was higher due to a high concentration of camp sites within a small area. According to the metabolic biomass estimation, yak grazing, followed by sheep and goats, are the primary contributors to grazing intensity in our study area. This is also partially reflected in the amount of variation in grazing intensity explained by yak dung patches and sheep/ goat dropping piles, particularly at lower elevation zones. The collection of dried yak dungs from nearby pastures may explain the lack of a relationship between current grazing intensity and old yak dung. However, we argue that the impact of dung collection is negligible in our study, because the nearest plot occurred $428 \mathrm{~m}$ from camps, which is beyond the normal distance for yak dung collection (T. Dorji, personal observation, summer 2010). Thus, we believe that dung collection was 
Table 5. Multiple regression model on relationships between real grazing intensity (dependent variable) and the grazing intensity proxies (distance from camp sites, number of old and fresh yak dung, number of active and abandoned pika (Ochotona curzoniae) burrows, and number of sheep and goat's dropping piles) and their interaction with landscape variables (elevation, aspect direction, and slope angle/steepness) (predictor variables) in central Tibet 2009. All grazing intensity proxy variables were log transformed.

\begin{tabular}{lrrrr}
\hline \multicolumn{1}{c}{ Model parameters } & Estimate & \multicolumn{1}{c}{$\mathrm{SE}^{1}$} & \multicolumn{1}{c}{$t$} & $P^{2}$ \\
\hline Intercept & 5.064 & 1.344 & 3.769 & 0.000 \\
Distance from camp sites & -0.516 & 0.190 & -2.712 & 0.009 \\
Old yak dung & 1.027 & 4.555 & 0.225 & 0.822 \\
Fresh yak dung & -1.353 & 4.680 & -0.289 & 0.773 \\
Active pika burrows & -3.546 & 5.037 & -0.704 & 0.484 \\
Abandoned pika burrows & 3.219 & 5.297 & 0.608 & 0.545 \\
Sheep and goat dropping piles & 9.421 & 16.627 & 0.567 & 0.573 \\
Old yak dung $\times$ elevation & 0.000 & 0.001 & -0.196 & 0.845 \\
Fresh yak dung $\times$ elevation & 0.000 & 0.001 & 0.308 & 0.759 \\
Active pika burrows $\times$ elevation & 0.001 & 0.001 & 0.708 & 0.482 \\
Abandoned pika burrows $\times$ elevation & -0.001 & 0.001 & -0.616 & 0.540 \\
Sheep and goat dropping piles $\times$ elevation & -0.002 & 0.003 & -0.570 & 0.571 \\
\hline
\end{tabular}

${ }^{1}$ Standard errors.

${ }^{2} P$ values for variables involved in the model.

at negligible intensity in the area where our plots were positioned.

The number of pika burrows did not significantly explain variation in real grazing intensity. Two mechanisms may explain this result. First, pika may move far from burrows for better forage areas when predation risk is low (Lovegrove and Painting 2008). Thus, the number of burrows may not represent in situ grazing intensity. Second, the number of burrows may correctly reflect pika grazing intensity, but pika grazing contributes little to variation in total grazing intensity. We believe the second mechanism may operate in our study system, because the presence of human and livestock in the region may force pikas to graze nearby their burrows. Thus, the number of burrows may represent the in situ pika density and their grazing intensity, but pika grazing contributes little to the total grazing intensity in the region. The metabolic biomass of pika also indicates that the relative contribution of pika to the total grazing intensity may be much lower than that of livestock in the study area. Nevertheless, the suitability of pika burrows in predicting real grazing intensity changed with elevation, and was highest at low elevation and had no suitability at higher elevations. This is conceivable, since pika prefer relatively flat terrain and our data also indicate that the number of pika burrows significantly decrease with elevation $\left(\beta_{1}=-0.03, P<0.05\right)$.

We acknowledge that the sample size $(n=75)$, the size of sampling plots $\left(100 \mathrm{~m}^{2}\right)$ and the range of distances from camp sites to sampling plot (428-2 $158 \mathrm{~m})$ we used may be regarded as weaknesses of our study. Even though, our sample size compares well with many other studies that have utilized proxies to estimate grazing intensity (Fernandez-Gimenez and Allen-Diaz 2001; Manthey and Peper 2010), as do the size of sampling plots (Hendricks et al. 2005; Hoshino et al. 2009; Manthey and Peper 2010), and the range of distance from herbivore congregation areas to sampling plots (FernandezGimenez and Allen-Diaz 2001; Sasaki et al. 2007; Manthey and Peper 2010; Tarhouni et al. 2010). We also acknowledge that a higher sampling effort could result in more of the proxies being statistically significantly related to real grazing intensity, but not that their suitability as proxies (as judged by their $R^{2}$ ) would increase notably. Finally, we acknowledge that the scale of our study is small, thus the inference may only be able to make in similar ecosystems at local to regional scales.

\section{IMPLICATIONS}

None of the examined proxies were sufficiently suitable for estimating grazing intensity in our study system. This may be an issue of concern since many studies use proxies to estimate effects of grazing on vegetation dynamics and ecosystem properties. We recommend others to be aware of the potential limitations of proxies, under conditions where measurements of real grazing intensity cannot be obtained. Our main point in this study is to show that even a considerable sampling effort in studies based on grazing proxies likely yield a data set with a large degree of uncertainty and an imprecise estimate of grazing intensity. We think that at least a pilot sampling is needed in order to test the suitability of proxies when estimating effects of grazing rangeland ecosystems. If a pilot sampling is not possible, then the distance from herbivore congregation areas may be used as proxy for grazing intensity if the herbivore distribution is random across the landscape. However, this may seldomly occur, unless the topography, vegetation and disturbance patters are homogeneous across the landscape. Because a mis-match between grazing and defecation sites of herbivores may be common, we warn against the use of herbivore excreta as a proxy for grazing, unless it is documented that herbivores graze and defecate at the same location. A similar mis-match situation may occur for the number of herbivore burrows as a proxy for grazing intensity.

\section{ACKNOWLEDGMENTS}

We thank Mr. Renzin Wangdui from the Agricultural and Animal Husbandry College, Tibet University, for fieldwork assistance in 2009. We also thank supporting staff (including Mr. Dorji Zhong Wang and Zonghu Huang) from Nam Tso Research station, Institute of Tibetan Plateau Research, Chinese Academy of Science for providing us a familylike environment during fieldwork. We also extend our great acknowledgment to the Associate Editor and two anonymous reviewers for their valuable comments.

\section{LITERATURE CITED}

Adler, P. B., and S. A. Hall. 2005. The development of forage production and utilization gradients around livestock watering points. Landscape Ecology 20:319-333.

Balley, D. W., J. E. Gross, E. A. Laca, L. R. Rittenhouse, M. B. Coughenour, D. M. Swift, AND P. L. Sims. 1996. Mechanisms that result in large herbivore grazing distribution patterns. Journal of Range Management 49:386-400.

Barnes, M. K., B. E. Norton, M. Maeno, and J. C. Malechek. 2008. Paddock size and stocking density affect spatial heterogeneity of grazing. Rangeland Ecology \& Management 61:380-388. 
Barnes, R. 2001. How reliable are dung counts for estimating elephant numbers? African Journal of Ecology 39:1-9.

Cincotta, R. P., P. J. V. Soest, J. B. Robertson, C. M. Beall, and M. C. Goldstein. 1991. Foraging ecology of livestock on the Tibetan Changtang: a comparison of three adjacent grazing Areas. Arctic and Alpine Research 23:149-161.

Cingolani, A. M., I. Noy-MeiR, AND S. Diaz. 2005. Grazing effects on rangeland diversity: a synthesis of contemporary models. Ecological Applications 15:757-773.

Coughenour, M. B. 1991. Spatial components of plant-herbivore interactions in pastoral, ranching, and native ungulate ecosystems. Journal of Range Management 44:530-542.

Doru, T., J. L. Fox, C. Richard, and K. Dhondup. 2010. An assessment of nonequilibrium dynamics in rangelands of the Aru basin, northwest Tibet, China. Rangeland Ecology \& Management 63:426-434.

Fernandez-Gimenez, M., and B. Allen-Diaz. 2001. Vegetation change along gradients from water sources in three grazed Mongolian ecosystems. Plant Ecology 157:101-118.

Fox, J. L., AND B.-J. BÅRDSEN. 2005. Density of Tibetan antelope, Tibetan wild ass and Tibetan gazelle in relation to human presence across the Chang Tang Nature Reserve of Tibet, China. Acta Zoologica Sinica 51:586-597.

Hendricks, H. H., W. J. Bond, J. Midgley, and P. A. Novelle. 2005. Plant species richness and composition a long livestock grazing intensity gradients in a Namaqualand (South Africa) protected area. Plant Ecology 176:19-33.

Hoshino, A., Y. Yoshinara, T. Sasaki, T. Okayasu, U. Jamsran, T. Okuro, and K. Takeuchi. 2009. Comparison of vegetation changes along grazing gradients with different numbers of livestock. Journal of Arid Environments 73:687-690.

JiAng, X. L. 1998. Relationship of population quantities of plateau pika with vegetation homogeneity. Acta Pratacultural Science 12:123-128. (In Chinese).

Johnson, R., And D. Wichern. 2007. Applied multivariate statistical data analysis. Upper Saddle River, NJ, USA: Pearson Prentice Hall. 773 p.

Kang, S., Y. Yang, L. Zhu, and Y. Ma. 2011. Modern environmental processes and changes in the Nam Co basin, Tibetan Plateau. Beijing, China: Beijing Meteorological Press. $349 \mathrm{p}$.

Karniel, A., U. Gilad, M. Ponzet, T. Svoray, R. Mirzadinov, and O. Fedorina. 2008. Assessing land-cover change and degradation in the Central Asian deserts using satellite image processing and geostatistical methods. Journal of Arid Environments 72:2093-2105.

KLEIBER, M. 1961. The fire of life: an introduction to animal energetics. New York, NY, USA: Wiley. $454 \mathrm{p}$.

LAl, C. H., AND A. T. Smith. 2003. Keystone status of plateau pikas (Ochotona curzoniae): effect of control on biodiversity of native birds. Biodiversity and Conservation 12:1901-1912.

LAnge, R. T. 1969. The piosphere: Sheep track and dung patterns. Journal of Range Management 22:396-400.

LI, X. L., AND B. N. Huang. 1995. The causes of "black soil patch" grassland in Qinghai province and management countermeasures. Grasslands of China 4:64-66. (In Chinese).

Long, R. J., D. G. Zhang, X. Wang, Z. Z. Hu, and S. K. Dong. 1999. Effect of strategic feed supplementation on productive and reproductive performance in yak cows. Preventive Veterinary Medicine 38:195-206.

Lovegrove, B., and S. Painting. 2008. Variations in the foraging behaviour and burrow structures of the Damara molerat Cryptomys damarensis in the Kalahari Gemsbok National Park. Koedoe: African Protected Area Conservation and Science 30:149-163.

Ludwig, J., R. EAger, R. Williams, and L. Lowe. 1999. Declines in vegetation patches, plant diversity, and grasshopper diversity near cattle watering-points in the Victoria river district, northern Australia. Rangeland Journal 21:135-149.

Manthey, M., and J. Peper. 2010. Estimation of grazing intensity along grazing gradients—-the bias of nonlinearity. Journal of Arid Environments 74:1351-1354.
Miehe, G., S. Miehe, K. Kaiser, L. Jianquan, and X. Zhao. 2008. Status and dynamics of the Kobresia pygmaea ecosystem on the Tibetan Plateau. Ambio 37:272-279.

Milchunas, D. G., and W. K. Lauenroth. 1993. Quantitative effects of grazing on vegetation and soils over a global range of environments. Ecological Monographs 63:328-366.

Misra, R. K., B. Singh, And V. K. Jain. 1998. Breed characteristics of Changthangi pashmina goat. Small Ruminant Research 27:97-102.

$\mathrm{NIE}, \mathrm{H}$. 2005. Study on the evolutionary ecology of small herbivorous mammals: life history strategy of plateau pika (Ochotona Curzoniae) [dissertation]. Hangzhou, China: Zhejiang University. 108 p. (In Chinese).

OмALIKo, C. 1981. Dung deposition, breakdown and grazing behavior of beef cattle at two seasons in a tropical grassland ecosystem. Journal of Range Management 34:360-362.

Pech, R. P., A. D. Arthur, Z. Yanming, and L. I. N. Hul. 2007. Population dynamics and responses to management of plateau pikas (Ochotona curzoniae). Journal of Applied Ecology 44:615-624.

Pickup, G., G. N. Bastin, and V. H. Chewings. 1998. Identifying trends in land degradation in non-equilibrium rangelands. Journal of Applied Ecology 35:365377.

PICKup, G., AND V. Chewings. 1994. A grazing gradient approach to land degradation assessment in arid areas from remotely-sensed data. Remote Sensing 15:597617.

Pineiro, G., J. M. Paruelo, and M. Oesterheld. 2006. Potential long-term impacts of livestock introduction on carbon and nitrogen cycling in grasslands of southern south America. Global Change Biology 12:1267-1284.

Pringle, H. J. R., and J. Landsberg. 2004. Predicting the distribution of livestock grazing pressure in rangelands. Austral Ecology 29:31-39.

Quinn, G. P., AND M. J. Keough. 2002. Experimental design and data analysis for biologists. Cambridge, UK: Cambridge University Press. 537 p.

R Development Core Team. 2012. R: A language and environment for statistical computing. Vienna, Austria: R Foundation for Statistical Computing.

Roxburgh, S. H., K. Shea, and J. B. Wilson. 2004. The intermediate disturbance hypothesis: patch dynamics and mechanisms of species coexistence. Ecology 85:359-371.

Sasaki, T., T. Okayasu, Y. Shirato, J. Undarmaa, and K. Takeuchi. 2007. Quantifying the resilience of plant communities under different grazing intensities in a degraded shrubland: a case study in Mandalgobi, Mongolia. Grassland Science 53:192195.

Sasaki, T., S. Okubo, T. Okayasu, U. Jamsran, T. Ohkuro, and K. Takeuchi. 2009. Management applicability of the intermediate disturbance hypothesis across Mongolian rangeland ecosystems. Ecological Applications 19:423-432.

Sun, F. D., R. J. Long, Z. G. Guo, W. Liu, Y. M. Gan, And W. Y. Chen. 2011. Effects of rodent activities on plant community and soil environment in alpine meadow. Acta Pratacultural Science 28:146-151. (In Chinese).

Tarhouni, M., F. Ben Salem, A. 0. Belgacem, and M. Neffati. 2010. Acceptability of plant species along grazing gradients around watering points in Tunisian arid zone. Flora 205:454-461.

Veeneklaas, R., A. Bockelmann, T. Reusch, and J. Bakker. 2011. Effect of grazing and mowing on the clonal structure of Elytrigia atherica: a long-term study of abandoned and managed sites. Preslia 83:455-470.

Wang, Y., X. M. Wang, Z. H. Wang, G. Patrick, T. Kenichi, and A. Graham. 2004. Primary study on habitat choice of plateau pika(Ochotona curzoniae). Journal of Sichuan University (Natural Science Edition) 5:57-60. (In Chinese).

Zhaо, X. Q., AND X. Zhou. 1999. Ecological basis of alpine meadow ecosystem management in Tibet: Haibei alpine meadow ecosystem research station. Ambio 28:642-647.

Zhou, H. K., Y. H. TAng, X. Q. ZhaO, And L. Zhou. 2006. Long-term grazing alters species composition and biomass of a shrub meadow on the Qinghai-Tibet Plateau. Pakistan Journal of Botany 38:1055-1069. 